\title{
Advanced numerical assessment of the permeability of pervious concrete
}

\author{
R. Pieralisi ${ }^{\mathrm{a}, *}$, S.H.P. Cavalaro ${ }^{\mathrm{b}, *}$, A. Aguado $^{\mathrm{b}}$ \\ a Departamento de Construção Civil, Universidade Federal do Paraná, Centro Politécnico, Bloco III, Jardim das Américas, 81531-980 Curitiba, PR, Brazil \\ b Departamento de Ingeniería Civil y Ambiental, E.T.S. Ingenieros de Caminos, Canales y Puertos, Universitat Politècnica de Catalunya, BarcelonaTech, Jordi Girona \\ Salgado 1-3, Módulo C1, Despacho 202, 08034 Barcelona, Spain
}

\section{A R T I C L E I N F O}

\section{Keywords:}

Pervious concrete

Permeability

Compaction process

Composition

DEM

CFD

\begin{abstract}
A B S T R A C T
The most singular characteristic of pervious concrete is its interconnected porosity that allows water to flow through at high rates. The objective of this paper is to develop and validate an advanced DEM-CFD model to assess the permeability of pervious concrete numerically, taking into account the influence of the composition and of the compaction process. An extensive experimental program with 1 aggregate grading size, 4 paste contents and 3 degrees of compaction was conducted to validate the numerical approach. Results show that the DEM-CFD model is capable of predicting the permeability depending on the variables considered here. Moreover, flow parameters derived from the numerical simulations help understand the experimental results. The study confirms that, instead of relying on trial and error experiments, it is possible to use advanced numerical models to accelerate the definition of mixes and the production process, reducing the time, efforts and costs required.
\end{abstract}

\section{Introduction}

Pervious concrete (PC) is material that has been used to insulate elements, to favor the permeability of surfaces [1-6] or to dissipate dynamic loadings [7-10]. Probably one of the most important applications is found in urban pavements as a sustainable alternative to reduce rain runoff, mitigate floods and recharge aquifers [1-6]. The most singular characteristic that favors the selection of this special type of concrete is its interconnected porosity - usually ranging from $15 \%$ to $30 \%[11]$ - that allows water to flow through at high rates $[12,13]$.

The porosity is achieved by reducing the amount of fines provided by the sand, as well as by the precise control of the level of compaction applied during execution. The compaction process governs the spatial distribution and sizes of the pores $[14,15]$, having a crucial influence in the final permeability $[11,16]$. Slight variations in the compaction applied may render a highly permeable PC into an almost watertight material.

In practice, the selection of the mix composition and of the compaction that guarantee the target permeability relies in costly and timeconsuming experimental studies based on trial and error. Instead, the assessment of the porosity and permeability coefficient depending on the composition and compaction process by means of numerical simulations is still a relatively unexplored field.

Several authors have simulated the water flow through PC in order to predict the permeability. Sumanasooriya et al. [17] proposed a method to reconstruct 3D models from planar images taken from hardened PC specimens. A 3D Stokes permeability solver for porous media was used to predict the permeability of the models once the mesostructure had been reconstructed. The permeability predicted numerically agreed with the obtained experimentally.

In line with that, Chung et al. [18] used computer tomography images to generate 3D models of PC samples. From this models, they proposed a method using low-order probability functions to generate reconstructed 3D model from the hardened specimens. The comparison between the permeability results obtained from Computational Fluid Dynamics (CFD) simulations of the original and reconstructed models showed similar values. Akand et al. [19] applied Fast Fourier Transformation to generate reconstructed 2D models of pervious concrete. They used CFD to predict the permeability of the models. The results obtained from the numerical simulations after calibration showed errors of $<8 \%$ in comparison with experimental results.

Despite the advances and good predictions, notice that studies from the literature count on reconstructed models, most of which depend on the image analysis of existing hardened specimens. In other words, they still require the experimental production of PC prior to assessing the permeability. Therefore, since the influence of the compaction process is not assessed numerically, the practical application of existing numerical methods for the design of PC mixes and the production process is limited. In order to overcome this drawback, it is necessary to integrate the model to predict the permeability with a model to

\footnotetext{
* Corresponding authors.

E-mail addresses: ricpieralisi@ufpr.br (R. Pieralisi), sergio.pialarissi@upc.edu (S.H.P. Cavalaro).
} 
numerically assess the meso-structure formed depending on the compaction applied. Hence, it will be possible to account for the important influence of the compaction in the assessment of the permeability without the need of resorting to experimental studies.

The objective of this paper is to develop and validate an advanced model to assess the permeability numerically, taking into account the influence of the mix composition and the compaction process. For that, an integrated model that combines discrete element modeling (DEM) and computational fluid dynamics (CFD) is proposed here. The DEM is used to simulate the compaction process of the PC in the fresh state and to obtain the meso-scale geometry, assuming some simplifications to account for the cement paste contact bridge and the approximation of the aggregates. The CFD estimates the flow profile and the permeability of the meso-scale geometry generated previously as an input.

In addition to the proposal of the DEM-CFD model, an extensive experimental program was conducted to estimate the permeability coefficient of PC with 1 aggregate grading size, 4 paste contents and 3 degrees of compaction. The experimental results were used to validate the DEM-CFD model. The conclusions derived from this study represent a step forward in the development of alternative approaches to design concrete mixes and define the production process for certain target properties. Instead of relying mainly on experiments, the study confirms that it is possible to use advanced numerical models to accelerate the definition of mixes and processes, increasing the likelihood of finding optimum solutions and reducing the time, efforts and costs required.

\section{Experimental program}

The production and characterization of the PC were performed at the Laboratory of Technology of Structures Luis Agulló (UPC). First, 4 PC compositions were defined and produced. The compositions used were selected in order to reproduce those typically found in practice. After the production, different degrees of compaction were applied by uniaxial compression. Finally, tests were conducted to evaluate the porosity, density and permeability of mixes. The materials, composition and production process applied here are based on those described by Pieralisi et al. [15].

\subsection{Materials properties}

The compositions used in this study are summarized in Table 1. Crushed limestone was selected as aggregate. The aggregate was sieved to ensure a particle size distribution between 5 and $12 \mathrm{~mm}$. In order to maximize the porosity achieved the aggregates were washed to eliminate remaining limestone dust after the sieving process.

Fig. 1a shows the surface aspect of the crushed limestone aggregates after the sieving and washing process. Fig. 1b shows the grading curve of the aggregate used. The density and the water absorption of the

Table 1

PC compositions and degrees of compaction.

\begin{tabular}{lllllll}
\hline Family & $\begin{array}{l}\text { Aggregate } \\
\left(\mathrm{kg} / \mathrm{m}^{3}\right)\end{array}$ & $\begin{array}{l}\text { Cement } \\
\left(\mathrm{kg} / \mathrm{m}^{3}\right)\end{array}$ & w/c & $\begin{array}{l}\text { Retardant } \\
\left(\mathrm{kg} / \mathrm{m}^{3}\right)\end{array}$ & $\mathrm{P} / \mathrm{A}$ & $\begin{array}{l}\text { Degree of } \\
\text { compaction (\%) }\end{array}$ \\
\hline L0.27 & 1400 & 300 & 0.27 & 3.0 & 0.27 & 10 \\
& 1400 & 300 & 0.27 & 3.0 & & 15 \\
& 1400 & 300 & 0.27 & 3.0 & 20 \\
$\mathrm{~L} 0.32$ & 1400 & 350 & 0.27 & 3.5 & 0.32 & 10 \\
& 1400 & 350 & 0.27 & 3.5 & & 15 \\
& 1400 & 350 & 0.27 & 3.5 & & 20 \\
L0.36 & 1400 & 400 & 0.27 & 4.0 & 0.36 & 10 \\
& 1400 & 400 & 0.27 & 4.0 & & 15 \\
& 1400 & 400 & 0.27 & 4.0 & & 20 \\
L0.41 & 1400 & 450 & 0.27 & 4.5 & 0.41 & 10 \\
& 1400 & 450 & 0.27 & 4.5 & & 15 \\
& 1400 & 450 & 0.27 & 4.5 & & 20 \\
\hline
\end{tabular}

crushed limestone after the washing process were $2640 \mathrm{~kg} / \mathrm{m}^{3}$ and $0.83 \%$, respectively. For all mixtures compositions the content of aggregates selected was fixed at $1400 \mathrm{~kg} / \mathrm{m}^{3}$. CEM II/A-L $42.5 \mathrm{R}$ was selected as the binder. The content of cement was another variable of the study, going from 300 to $450 \mathrm{~kg} / \mathrm{m}^{3}$, in intervals of $50 \mathrm{~kg} / \mathrm{m}^{3}$.

The water-to-cement ratio $(\mathrm{w} / \mathrm{c})$ was the same for the compositions teste here. This intended to assure a similar rheology of the cement paste surrounding the aggregates in all of them. Such consideration simplifies the numerical simulation and the validation of the models using the results from the experimental program.

The amount of water to correct the absorption of the crushed limestone was added to the mixing water. Moreover, $1 \%$ of retardant by cement weight was added in order to diminish variations in the fresh state properties of the concrete during the compaction of the several specimens that had to be produced for each composition.

One of the main variable of the study related with the composition of the pervious concrete was the ratio between paste (cement + water) and aggregate by weight (P/A ratio), which ranged from 0.27 to 0.41 . This parameter affects the compaction process and may also have repercussion in the final permeability. In theory, for the same degree of compaction, a composition with bigger P/A ratio should present smaller permeability. According to the $\mathrm{P} / \mathrm{A}$ ratio, the mixture compositions were divided in 4 families: namely L0.27, L0.32, L0.36 and L0.41 (see Table 1).

The mixing process was the same for all mixes. The PC was prepared in a planetary mortar mixer type $65 / 2 \mathrm{~K}-3$, using a container with nominal capacity of $65 \mathrm{l}$. Paddle rotation and planetary rotation were $150 \mathrm{rpm}$ and $40 \mathrm{rpm}$, respectively. First, cement and aggregates were mixed during $60 \mathrm{~s}$. Then, $70 \%$ of the total water was added and mixed during $30 \mathrm{~s}$. Finally, the rest of the water and the retardant was added and mixed during $60 \mathrm{~s}$. Batches of approximately 201 were produced for each mix from Table 1.

The fresh PC obtained was immediately placed in cylindrical molds (with height equal to $200 \mathrm{~mm}$, diameter equal to $100 \mathrm{~mm}$ and that followed the specifications from UNE-EN 12390-1 [20]), in three layers. The excess of material surpassing the top of the mold was removed to ensure that the initial height of specimens was $200 \mathrm{~mm}$. This removal was performed with care, to avoid introducing compaction forces. The weight of each specimen was measured to achieve comparable levels of initial porosity in mixtures with the same $\mathrm{P} / \mathrm{A}$ ratio.

The second variable of the experimental program that holds close relation with the permeability is the degree of compaction (DoC), calculated here as the ratio between the reduction of height and the initial height of the specimen. In order to guarantee homogeny conditions in all specimens, the compaction was applied in a hydraulic press with $10 \mathrm{kN}$ of nominal load capacity and with closed loop capability. Uniaxial compaction with displacement control was employed to achieve 3 values of DoC: 10, 15 and 20\% (see Table 1).

In total, 12 mixes were produced considering the combination of variables described. For each of them, 10 specimens were cast. After the compaction process, the molds were wrapped in a plastic bag during the first $24 \mathrm{~h}$ to ensure good curing conditions. Then, specimens were demolded and submerged in water for 98 days.

\subsection{Test methods}

After the curing period, specimens were tested for their porosity and density (measured according to ASTM C1754 [21]). Once this test was finished, they were characterized for the permeability. Notice that the assessment of permeability does not follow a specific standard due to the lack of widely accepted standard testing procedures available in the scientific community for that purpose. All specimens were kept under submerged curing in between tests.

\subsubsection{Porosity and density}

Before the determination of the porosity and density, specimens 






(b)
Fig. 1. Surface aspect (a) and the grading curve (b) of crushed limestone. were removed from the submerged curing and left to dry under laboratory conditions for $72 \mathrm{~h}$ [11,21-23]. Then, their diameter, height and dry weight were measured.

Subsequently, specimens were submerged in water for $48 \mathrm{~h}$, until they were completely saturated. Finally, their buoyant weight was measured using a hydrostatic weight. The porosity (P) and the density (D) of each specimen was estimated with Eqs. (1) and (2), respectively. In these equations, $W_{1}$ represents the dry weight, $W_{2}$ is the buoyant weight, $\varnothing_{s}$ is the diameter of the specimen, $L_{s}$ represents the height of the specimen and $\rho_{w}$ is the density of the water at $25{ }^{\circ} \mathrm{C}$. This procedure was applied in 10 specimens of each composition and DoC, totalizing 120 determinations of density and porosity.

$P=\left[1-\frac{4 \cdot\left(W_{1}-W_{2}\right)}{\rho_{w} \cdot \pi \cdot \varnothing_{s}^{2} \cdot L_{s}}\right] \cdot 100$

$D=\frac{4 \cdot W_{1}}{\pi \cdot \varnothing_{s}^{2} \cdot L_{S}}$

\subsubsection{Permeability}

Two types of setups are commonly used to measure the permeability of PC: falling head permeameter and constant head permeameter. The constant head permeameter was adopted here to simplify the numerical simulations and the validation, since it is easier to simulate. The method consists of measuring the amount of water that passes through the specimen in a certain time interval. Based on the study by other authors [24-28], the apparatus depicted in Fig. 2a was designed to perform this test.

For better understanding the setup, Fig. $2 \mathrm{~b}$ depicts a cross-section of the apparatus, which was composed by 3 parts: top tube with inlet, water proof layers and bottom tube. The specimen was fixed in the middle of the two tubes using a waterproof adhesive aluminum tape at both extremities (Fig. 2c). The top tube with inlet was placed above the specimen to guarantee that the water level was maintained at $220 \mathrm{~mm}$ above the top face. This water level was defined in order to avoid the turbulent flow. The bottom tube was positioned bellow the specimen with a water outlet that could be either opened or closed.

Additional coating was installed around the specimen to reduce the water flow along the lateral side of the sample, which could bias the permeability assessment. First, waterproof adhesive aluminum tape was used to involve the whole circumferential side of the specimen (Fig. 2d). Next, the specimen was wrapped with two layers of crepeadhesive tape to protect the adhesive aluminum tape (Fig. 2e). A rubber band was placed around it in order to provide a slight lateral pressure that further limits the lateral flow. After that, the specimen was fixed with five adjustable clamps (Fig. 2f). The equipment was fixed to the wall to ensure the verticality (Fig. $2 \mathrm{~g}$ ).

Once the setup was completed, the opening of the bottom tube was closed. Next, the volume of water necessary to fill the bottom tube and the pore spaces of the specimen was measured $\left(q_{1}\right)$. Then, the apparatus was completely filled with water and the bottom tube was opened.
Finally, the volume of water that passed through the specimen in $60 \mathrm{~s}$ was measured $\left(q_{2}\right)$.

The permeability ' $K$ ' was estimated using Darcy's law according with Eq. (3). In this equation $q$ is the difference between both measured volumes of water $\left(q_{2}-q_{1}\right)$, h is the distance between the bottom of the specimen and the water level ( $W L$ ) and $\mathrm{t}$ is time interval (60 s). For each mix composition and degree of compaction, 10 specimens were characterized, totalizing 120 assessments of the permeability.

$K=\frac{4 \cdot q \cdot L_{s}}{\pi \cdot \varnothing_{s}^{2} \cdot h \cdot t}$

\subsection{Experimental results}

Table 2 shows the average results of porosity and permeability coefficient depending on the P/A ratio and the DoC. The coefficient of variation (CV) calculated is presented between parenthesis. ANOVA and Tukey HSD Test were performed to evaluate if the differences observed between composition and compaction process applied was significant. The significance level considered was 0.05 .

For the same DoC, the increase in the $\mathrm{P} / \mathrm{A}$ ratio leads to a reduction of both the porosity and the permeability ( $p$-value $\leq 0.001$ in all ANOVA comparisons and $p$-value $<0.05$ for $72.2 \%$ of multiple comparisons in the Tukey's HSD test). This is reasonable since higher values of $\mathrm{P} / \mathrm{A}$ ratio indicates that a bigger volume of cement paste is available in the system, reducing the porosity available and the free-space for the water to flow through.

The DoC has the opposite effect. For the same composition, an increase in the compaction applied produces a reduction of both the porosity and the permeability ( $p$-value $<0.0001$ in all ANOVA comparisons and $p$-value $<0.05$ for $91.7 \%$ of multiple comparisons in the Tukey's HSD test). This is explained by the fact that a higher compaction tends to approximate the particles formed by aggregate surrounded by paste. This increases the number of contacts, diminishes the porosity and reduces the free-space left for water to flow.

The influence of the degree of compaction is slightly higher than that of the P/A ratio. Supposing a linear regression, in the average, every $10 \%$ reduction of the maximum DoC tested $(20 \%)$ produces a variation of $3.9 \%$ in the porosity and $12.7 \%$ in the permeability. Conversely, every $10 \%$ decrease of the P/A ratio over the maximum tested here $(0.413)$ produces a variation of $3.6 \%$ in the porosity and $11.8 \%$ in the permeability. The results also show that, in relative terms, the influence over the permeability coefficient is around 3 times higher than over the porosity of the system.

This outcome suggests that the change of the permeability is not related solely to the porosity of the system, also being affected by the modification of the tortuosity of the porous network. In fact, the upsurge in the number of contacts induced by the additional compaction would increase the tortuosity of the porous network, further contributing to the reduction of the permeability.

Fig. 3 shows the relation between permeability coefficient and 


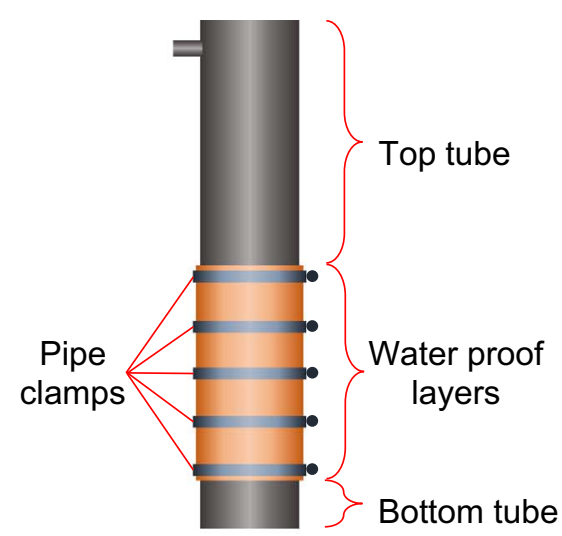

(a)

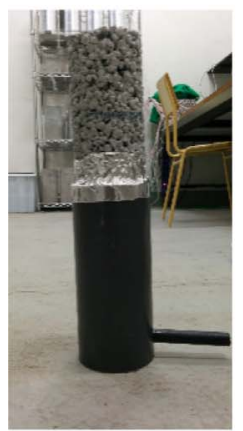

(c)

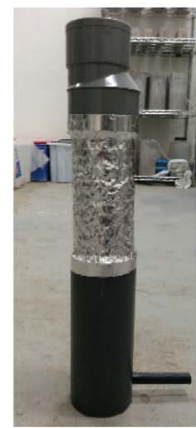

(d)

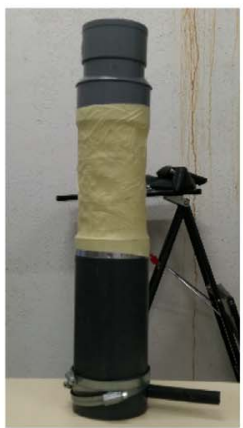

(e)

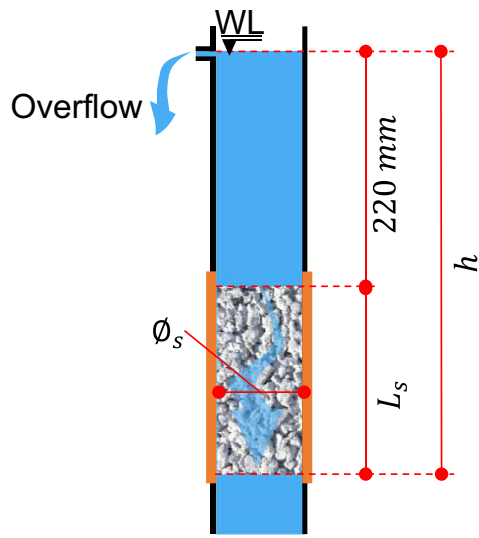

(b)

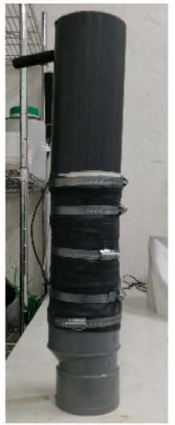

(f)

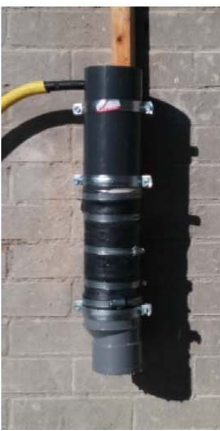

(g)

Fig. 2. Constant head permeameter scheme (a), cross section scheme (b) and assembly process (c-g).

Table 2

Experimental results and CV (between parenthesis).

\begin{tabular}{|c|c|c|c|c|c|}
\hline \multirow[t]{2}{*}{ Prop. } & \multirow[t]{2}{*}{ DoC (\%) } & \multicolumn{4}{|c|}{ Experimental } \\
\hline & & L0.27 & L0.32 & L0.36 & L0.41 \\
\hline \multirow[t]{3}{*}{ Porosity P (\%) } & 20 & $\begin{array}{l}33.83 \\
(5.6 \%)\end{array}$ & $\begin{array}{l}34.62 \\
(5.7 \%)\end{array}$ & $\begin{array}{l}31.68 \\
(4.1 \%)\end{array}$ & $\begin{array}{l}28.18 \\
(5.2 \%)\end{array}$ \\
\hline & 15 & $\begin{array}{l}36.60 \\
(4.2 \%)\end{array}$ & $\begin{array}{l}38.68 \\
(2.0 \%)\end{array}$ & $\begin{array}{l}35.58 \\
(5.4 \%)\end{array}$ & $\begin{array}{l}33.89 \\
(5.0 \%)\end{array}$ \\
\hline & 10 & $\begin{array}{l}39.63 \\
(3.2 \%)\end{array}$ & $\begin{array}{l}41.05 \\
(3.2 \%)\end{array}$ & $\begin{array}{l}38.62 \\
(2.0 \%)\end{array}$ & $\begin{array}{l}34.84 \\
(3.1 \%)\end{array}$ \\
\hline \multirow[t]{3}{*}{$\begin{array}{l}\text { Perm. Coef. K } \\
(\mathrm{mm} / \mathrm{s})\end{array}$} & 20 & $\begin{array}{l}13.49 \\
(20.7 \%)\end{array}$ & $\begin{array}{l}13.69 \\
(14 \%)\end{array}$ & $\begin{array}{l}8.24 \\
(14.1 \%)\end{array}$ & 8.47 (9.9\%) \\
\hline & 15 & $\begin{array}{l}18.54 \\
(18.6 \%)\end{array}$ & $\begin{array}{l}18.00 \\
(6.1 \%)\end{array}$ & $\begin{array}{l}16.79 \\
(14.4 \%)\end{array}$ & $\begin{array}{l}14.36 \\
(9.1 \%)\end{array}$ \\
\hline & 10 & $\begin{array}{l}26.28 \\
(4.5 \%)\end{array}$ & $\begin{array}{l}21.12 \\
(8.2 \%)\end{array}$ & $\begin{array}{l}19.19 \\
(7.6 \%)\end{array}$ & $\begin{array}{l}15.32 \\
(11.3 \%)\end{array}$ \\
\hline
\end{tabular}

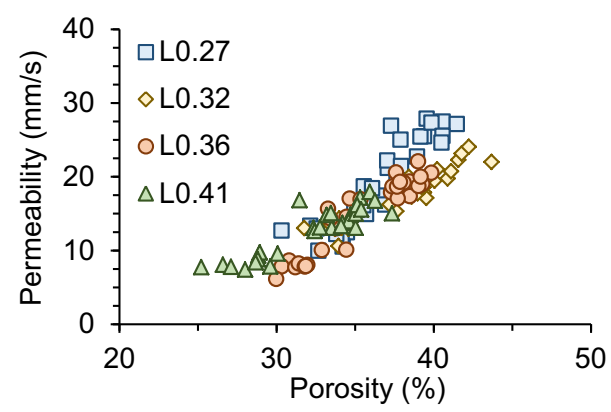

Fig. 3. Experimental variation of permeability coefficient in relation to the porosity. porosity, considering individual results derived from the experimental program for the same specimen The permeability varies from 5 to $30 \mathrm{~mm} / \mathrm{s}$, increasing with the porosity (correlation coefficient equal to 0.87 , considering all results). This confirms the observations described previous paragraphs, possibly indicating the influence of an additional parameter (tortuosity) that further contributes to the variation of the permeability.

\section{DEM simulation of the compaction process}

In this section, the model for simulating the compaction process of the pervious concrete in the fresh state is discussed. Then, the mesh generation process is presented. Finally, the boundary conditions and the input parameters for the flow simulation were defined.

\subsection{Geometrical model}

\subsubsection{Compaction model}

The method proposed by Pieralisi et al. [15] was used to simulate the compaction process of pervious concrete. This method takes into account parameters related to the composition of the pervious concrete, like the aggregate grading curve, the P/A ratio and the rheology of the cement paste. Simulations were performed using DEM $[29,30]$. YADE [31] was selected as open-source framework for these simulations.

Some simplifications were introduced to reduce the computational cost of the simulation. Most of them were related to the shape of aggregates. A bi-phasic spherical particle shown in Fig. 4a was used $[14,15,32,33]$. It was formed by an inner core with radio $R_{a g}$ surrounded by an external layer with thickness $t_{e q}$. The former represents the aggregate and the later represents the cement paste.

The grading curve of the aggregate (shown in Fig. 1) was discretized 
(a) Particle definition

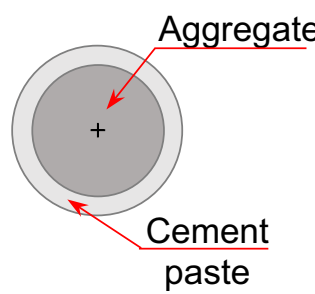

(b) Burger Model

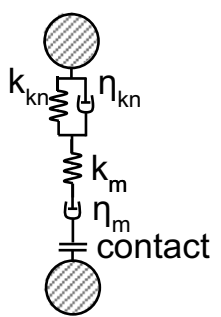

(c) Bingham-Hocke Model



Fig. 4. Particle definition (a) and contact models (b and c).

in 3 zones. For each zone, an equivalent diameter and the number of particles was assessed using a weighted calculation of masses. The average equivalent diameters of $4.66 \mathrm{~mm}, 5.81 \mathrm{~mm}$ and $6.48 \mathrm{~mm}$ were used. The volume of aggregates corresponding to each equivalent diameter was $17.94 \%, 35.16 \%$ and $46.89 \%$, respectively.

The P/A ratio should affect the thickness of paste involving the aggregates. The equivalent thickness $\left(t_{e q}\right)$ of paste around the aggregate was calculated with the proportionality coefficient $\alpha_{e q}$ following the procedure proposed by Klein et al. [34] and adapted by Pieralisi et al. [15]. In this sense, $\alpha_{e q}$ was estimated through Eq. (4) with the volume of aggregates $\left(V_{a g}\right)$ and the volume of cement paste or mortar $\left(V_{p}\right)$ used in the composition. Once the aggregates sizes and the $\alpha_{e q}$ were defined, the $t_{e q}$ was calculated for each aggregate size using Eq. (5). Table 3 presents the $\alpha_{e q}$ calculated for each P/A ratio used in the experimental results and example of $t_{e q}$ for specific diameters of aggregate particles.

$\alpha_{e q}=\sqrt[3]{1+\frac{V_{p}}{V_{a g}}}-1$

$t_{e q}=R_{a g} \bullet \alpha_{e q}$

In the compaction process simulation with DEM, particles may interact with each other. The interactions are governed by force-displacement laws. A Kelvin-Voigt model in line with an additional spring and a dumper (Fig. 4b) was used to simulate the normal interaction between the external layers of the particles, whereas a purely elastic interaction law simulates the contact between the inner cores. A modified Bingham-Hocke law (Fig. 4c) was applied to model the tangential contact. For detailed description and validation of these force-displacement laws, consult Pieralisi et al. [15].

Numerical simulations of the compaction process emulated the experimental procedure described in Section 2.1. It started with the dropping of the particles inside a cylindrical mold. Particles located above the upper limit of the mold were removed by means of a plane that passed horizontally above the specimen. Then, a cylindrical plate descended, compacting the particles. The model was compacted until the desired DoC. In order to describe the position of the particles in a 3D Cartesian coordinate system, two parameters were determined throughout the analysis: the center coordinates and the radius of the particles.

The input parameters used in this work to simulate the compaction process of the pervious concrete and to generate the 3D compacted

Table 3

$\alpha_{e q}$ used in the simulation and example values of $\mathrm{t}_{\mathrm{eq}}$ for specific particle diameters.

\begin{tabular}{llllll}
\hline Family & \multirow{2}{*}{ P/A ratio } & \multirow{2}{*}{$\alpha_{e q}$} & \multicolumn{2}{l}{$t_{e q}(\mathrm{~mm})$ for particle with diameter: } \\
\cline { 3 - 6 } & & & $4 \mathrm{~mm}$ & $8 \mathrm{~mm}$ & $12 \mathrm{~mm}$ \\
\hline $\mathrm{L} 0.27$ & 0.27 & 0.08272 & 0.331 & 0.662 & 0.993 \\
$\mathrm{~L} 0.32$ & 0.32 & 0.09512 & 0.380 & 0.761 & 1.141 \\
$\mathrm{~L} 0.36$ & 0.36 & 0.10715 & 0.429 & 0.857 & 1.286 \\
$\mathrm{~L} 0.41$ & 0.41 & 0.11887 & 0.475 & 0.951 & 1.426 \\
\hline
\end{tabular}

Table 4

Parameters used in the simulation according with previous calibration by Pieralisi et al. [8].

\begin{tabular}{lll}
\hline Parameter & \multicolumn{2}{l}{ Value } \\
\hline External layer & $B_{k, k n}$ & $5.23 \times 10^{10} \mathrm{~N} /\left(\mathrm{m} \cdot \mathrm{m}^{3}\right)$ \\
& $B_{\eta, k n}$ & $1.43 \times 10^{10} \mathrm{~N} \cdot \mathrm{s} /\left(\mathrm{m} \cdot \mathrm{m}^{3}\right)$ \\
& $B_{k, m n}$ & $7.60 \times 10^{11} \mathrm{~N} /\left(\mathrm{m} \cdot \mathrm{m}^{3}\right)$ \\
& $B_{\eta, m n}$ & $6.18 \times 10^{11} \mathrm{~N} \cdot \mathrm{s} /\left(\mathrm{m} \cdot \mathrm{m}^{3}\right)$ \\
& $\alpha_{\text {fric,e }}$ & 0.6 \\
& $F_{y}$ & $1.0 \times 10^{6}$ \\
& $\alpha_{e q}$ & Values in Table 3 \\
Inner core & $k_{n, \text { inner }}$ & $5.5 \times 10^{10} \mathrm{~N} / \mathrm{m}$ \\
& $\alpha_{\text {fric,i }}$ & 0.75 \\
\hline
\end{tabular}

models are presented in Table 4. $B_{k, k n}$ and $B_{\eta, k n}$ are respectively the elastic and viscous coefficients of the spring and the dumper of the Kelvin-Voigt model in the normal direction. $B_{k, m n}$ and $B_{\eta, m n}$ are the analogous coefficients for the spring and the dumper placed in line with the Kelvin-Voigt model, respectively. $k_{n \text {,inner }}$ is the elastic coefficient of the contact between inner cores. $F_{y}$ is the yield stress for the tangential interaction in the modified Bingham-Hocke law. $\alpha_{\text {fric }, e}$ and $\alpha_{\text {fric }, i}$ are the friction coefficients that simulates the tangential forces in the same model when the contact occurs between external layers and between inner cores, respectively. All parameters were calibrated and validated as described in Pieralisi et al. [15].

Notice that the aggregate type, grading curve, type of cement and $\mathrm{w} / \mathrm{c}$ from the experimental program presented here (Section 2.1) was the same used by Pieralisi et al. [15] to calibrate and validate the compaction model. 10 compacted models with different degrees of compaction were generated with different $\mathrm{P} / \mathrm{A}$ ratio.

\subsubsection{Meso-structure}

In the compaction process, initially the contacts between particles occurs in the form of an overlap at the external layers that represents the cement paste around the aggregates. As the distance between particles decreases, the inner cores (aggregates) push the surrounding layer away from the point of contact due to the visco-elastic rheology of the cement paste. This causes a cement paste redistribution, a lateral volume increase and the formation of a meniscus called contact bridge (CB).

Fig. 5a presents an image of a pervious concrete specimen. In this figure, 3 types of CBs are depicted in blue. The first one, represented in Fig. 5 b, was formed by the interaction between a particle and the wall of the mold. The second type occurs when two particles overlap with each other (see Fig. 5c). The third type occurs when three or more entities (particles and/or wall) overlap simultaneously, as depicted in Fig. $5 d$.

The 3d meso-structure used in the DEM was formed by the solid phases (aggregates and cement paste) and the pore phase (voids represented by the hollows between particles). The increase of the $\mathrm{CB}$ affects the interaction between particles or between the particles and the wall, which was considered implicitly in the contact law. In other 


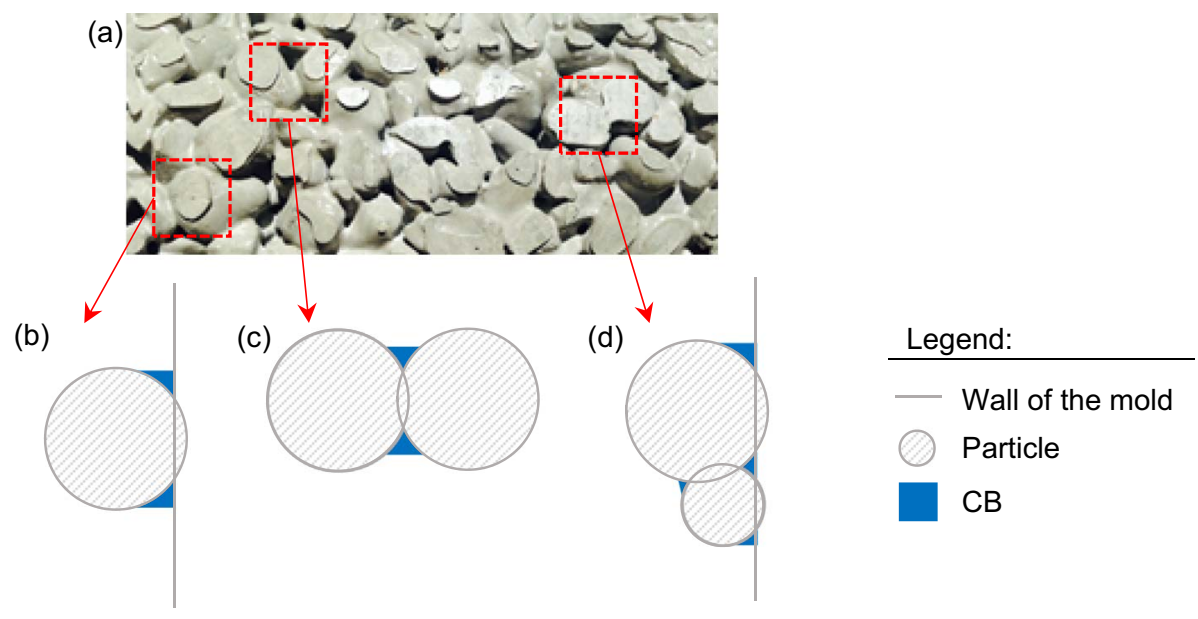

Fig. 5. Types of CBs. (For interpretation of the references to color in this figure, the reader is referred to the web version of this article.) words, the formation of the $\mathrm{CB}$ and the resultant geometry was not taken into account explicitly in the DEM simulation by Pieralisi et al. [15].

Even though this simplification reduces the calculation cost without negative repercussion in the assessment of the compaction process, the same is not true for the simulation of the fluid flow through the material. In this last case, the proper consideration of the geometry of the $\mathrm{CB}$ was required since it affects the total volume of voids and tortuosity of the system, being directly related with the porosity and permeability. Should this be ignored, significant differences may arise between model and reality. Therefore, some adjustments on the solid phase of the compacted model are needed for a better geometrical representation of the PC for the flow simulations.

The algorithm developed here to represent the 3D formation of $\mathrm{CB}$ analyzes the interaction between two entities (particle-particle or particle-wall) at a time. For nomenclature purposes, the interaction between two particles was called sphere-sphere (S-S) and the interaction between particle and wall was named sphere-wall (S-W).

To assess the $\mathrm{CB}$, a simple geometric calculation was performed. It assumed that the volume of cement paste located in the overlap region equals the volume that should be redistributed around the contact point. Fig. 6a illustrates this for an S-S interaction. In this figure, the overlap volume is hatched in red and the $\mathrm{CB}$ formation is painted in blue.

Fig. $6 \mathrm{~b}$ presents the cross section of the interaction S-S. Once the volume of overlap was estimated for a certain interaction, the volume of the CB was also known. Then, the position of the points $P_{2}$ and $P_{3}$ were determined. The volume of the object formed by the revolution of the triangle $P_{1}-P_{2}-P_{3}$ (CB region painted in blue in Fig. 6a) around the y-axis was then calculated.

To simplify this calculation, the angle $\omega$ that represents the increment was assumed equal for both particles in contact. This consideration implies a negligible error as long as the thickness of the cement paste layer is small in comparison with the diameter of the aggregate and the sizes of particles do not vary by one order of magnitude. Even though this is the common case with PC, if such conditions are not fulfilled, a more precise calculation should be applied to estimate the angle $\omega$ for each particle. Fig. $6 \mathrm{c}$ depicts the interaction S-W. Notice that the volume of redistributed paste may be calculated in an analogous way.

With the geometrical properties of the particles and the CB for each interaction, a VBA code (integrated in SolidWorks) generates the solid geometry. This model consists of a unified volume of all particles and the CBs, as presented in Fig. 7.

\subsection{CFD mesh generation}

The porous phase (voids) and the surface of the solids were meshed for the CFD analysis. This is necessary since the water flow is governed by the pores. The mesh was generated using SolidWorks Flow Simulation - a 3D CFD solver that uses a Cartesian Mesh (CM) with octree refinement. Dassault Systèmes [35] showed that the Cartesian Mesh requires less elements to achieve the same accuracy as the obtained in other CFD mesh generation approaches. This also contributes to the reduction of the computational effort.

The mesh generation initiated with a division of the porous domain into a series of coarse cuboids formed by intersection of planes parallel to the axis of coordinate system. Next, this coarse mesh was refined. The refinement process consisted of dividing a specific cuboid into eight or more geometrically similar cuboids. The criteria used in the software to define the cuboids that should be divided followed those proposed by Dassault Systèmes [35] and Sabachkin and Dumnov [36]. Further details on the validation process of meshing and refinement used in Flow Simulation may be found in [35].

Here, a numerical study was performed to investigate the influence of the mesh refinement over the permeability results for a typical PC model derived from the DEM compaction model from Section 3.1. Fig. 8a presents the relation between the number of elements of a mesh and the permeability coefficient.

In order to achieve different levels of refinement, the minimal size of the element was changed. To extrapolate the minimal size of the element to other models that may present a totally different geometry, the results of the sensibility analysis was represented in terms of the number of elements $\left(N_{\text {Elem }}\right)$ that fits inside the diameter of smallest aggregate particle $\left(\varnothing_{\min }\right)$ of the system. Fig. $8 \mathrm{~b}$ and Fig. $8 \mathrm{c}$ show crosssections of the same geometry discretized using meshes with $4 N_{\text {Elem }} /$ $\varnothing_{\min }$ and $16 N_{\text {Elem }} / \varnothing_{\min }$. An increase in the number of elements allows a finer reproduction of the porous surface.

Fig. 8 a shows the permeability coefficient estimated numerically for different levels of mesh refinement. Similar results are obtained for meshes with $N_{E l e m} / \varnothing_{\text {min }}$ bigger than 12 . Taking that into account, the mesh discretization used here for all simulations was set to $16 N_{\text {Elem }} /$ $\varnothing_{\text {min }}$

The 3D model of a typical specimen is presented in Fig. 8d. Notice that a region was included at the top and the bottom of the model without any particle. These regions were defined in order to avoid the turbulent flow at the entrance and to guarantee the direction of the flow, emulating what should occur in the tests from the experimental program. 


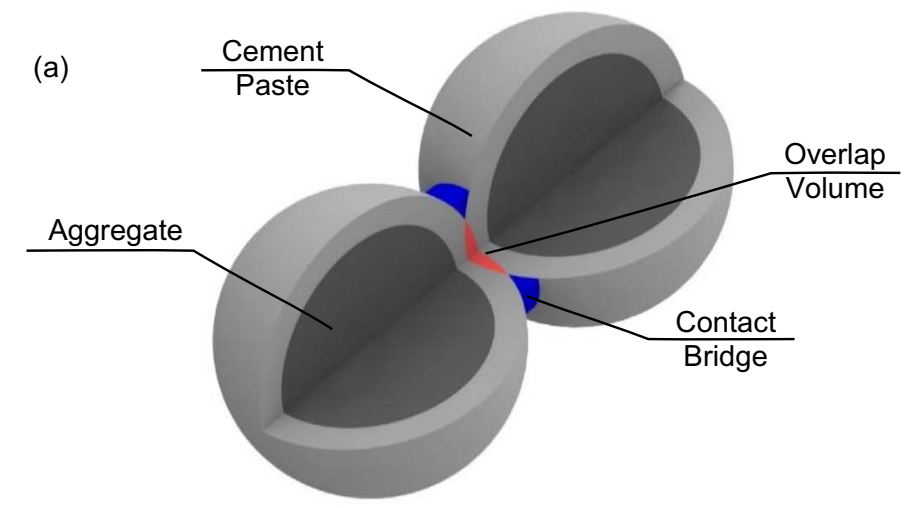

(b)



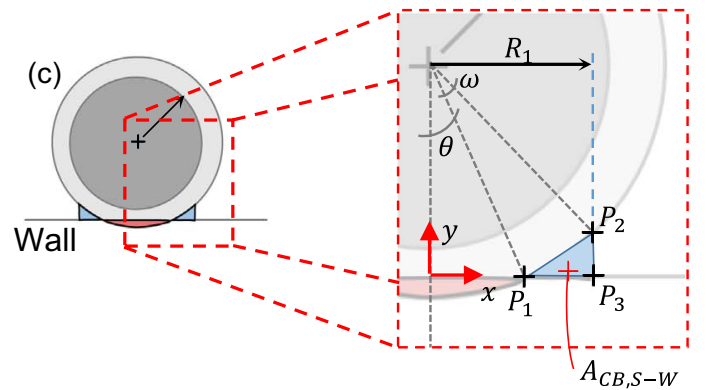

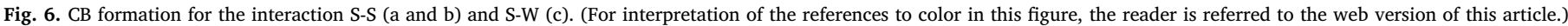



Fig. 7. Geometrical model of a pervious concrete specimen for a certain DoC

\subsection{Input parameters and boundary conditions}

In this study, water at $25{ }^{\circ} \mathrm{C}$ was used as the fluid. The roughness applied at the surface of the pores was $20.0 \mu \mathrm{m}$, taking into account the studies by Apedo et al. [37]. Gravity was assumed as $9.81 \mathrm{~m} / \mathrm{s}^{2}$ in the direction $\mathrm{Z}$, which was parallel to the axis of the cylindrical specimens. The boundary conditions imposed consisted of the pressures at inlet and outlet prescribed at the top and bottom planes normal to the $\mathrm{Z}$ direction, as depicted in Fig. 8d. This boundary conditions correspond to the static pressure generated in the experimental program as a consequence of the constant height of the water level.

In this work, SolidWorks Flow Simulation was used as a solver. This software, solves the Navier-Stokes equation to predict the flow for turbulent and laminar regimes. The formulation of the model is described in detail in [38].

The CFD solution reached the steady-state flow condition when the difference of the average velocity between two consecutive interactions was smaller than $1.0 \times 10^{-6}$. After that, the volume flow was calculated and introduced in the Darcy's Law (Eq. (6)) to estimate the permeability ' $k_{m}$ ' (in $\mathrm{m}^{2}$ ). In this equation, $Q$ is the volume flow rate in $\mathrm{m}^{3} /$ $\mathrm{s}, \mu$ is the dynamic viscosity of the water expressed in Pas, $L_{m}$ is the height of the model expressed in $\mathrm{m}, A_{m}$ is the cross section area of the model expressed in $\mathrm{m}^{2}$ and $\Delta p$ is the pressure gradient expressed in $\mathrm{Pa}$.

$k_{m}=\frac{Q \cdot \mu \cdot L_{m}}{A_{m} \cdot \Delta p}$

The permeability coefficient of the model ' $K_{m}$ ' (or hydraulic conductivity expressed in $\mathrm{mm} / \mathrm{s}$ ) was obtained according to Eq. (7). In this equation, $\rho_{w}$ is the density of water in $\mathrm{kg} / \mathrm{m}^{3}$ and $g$ is the acceleration of gravity expressed in $\mathrm{m} / \mathrm{s}^{2}$.

$K_{m}=k_{m} \cdot \frac{\rho_{w} \cdot g}{\mu} \cdot 1000$ 


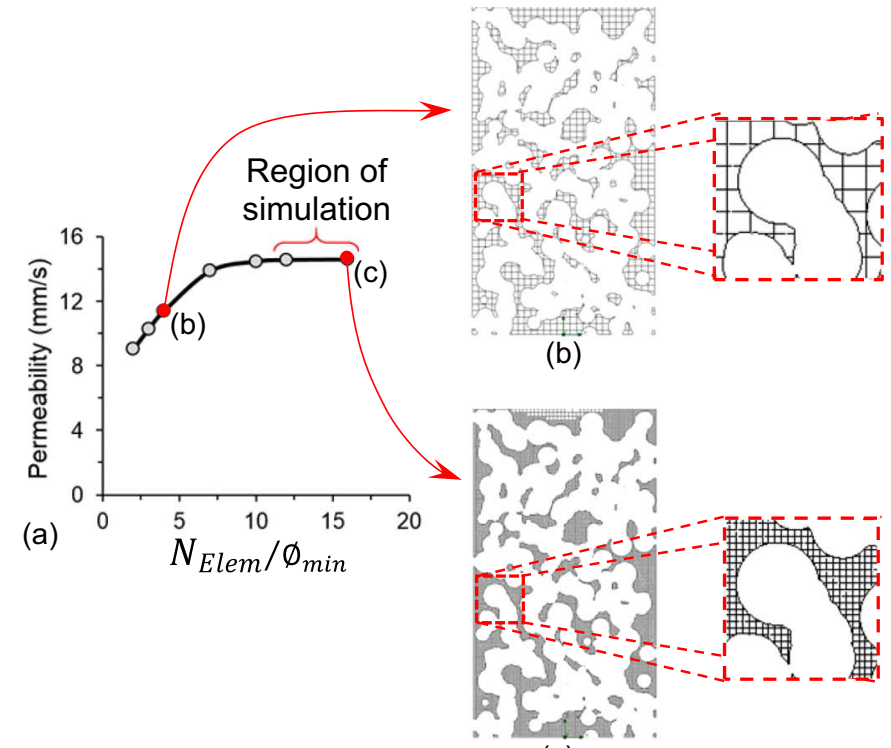

(c)

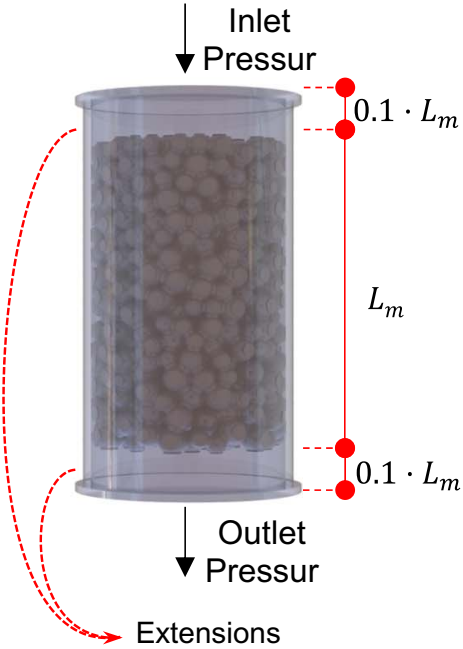

(d)

Fig. 8. Influence of the mesh discretization over the results (a to c) and dimensions of the diametric section of the model (d).

\section{Numerical simulation}

First, the numerical results are presented and compared with the experimental results of the permeability. Then, a study regarding the relation between the geometrical properties of the models and the fluid flow velocity is presented. Finally, the numerical results of the fluid flow tortuosity are analyzed.

\subsection{Numerical results}

Table 5 shows the numerical results of porosity and permeability coefficient. Although the average porosity decreases with the P/A ratio, differences are not enough to be considered statistically significant in all cases. Analogous observations are found for the permeability. A $p$ value $>0.05$ was found in the ANOVA for the porosity and permeability when the P/A ratio increases for a DoC of $10 \%$. Nevertheless, a $p$-value $<0.05$ in the ANOVA was estimated for the influence of the P/ A ratio on the permeability in case of DoC of $20 \%$.

This results suggests that the influence of the A/P ratio becomes more evident as the DoC increases. Since the porous space left in the microstructure is reduced for high DoC, the influence of any increment in the volume of paste filling the voids is proportionally bigger. In contrast, as more voids are available in the microstructure for low

Table 5

Numerical results and CV (between parenthesis).

\begin{tabular}{|c|c|c|c|c|c|}
\hline \multirow[t]{2}{*}{ Prop. } & \multirow[t]{2}{*}{ DoC (\%) } & \multicolumn{4}{|c|}{ Experimental } \\
\hline & & L0.27 & L0.32 & L0.36 & L0.41 \\
\hline \multirow[t]{3}{*}{ Porosity P (\%) } & 20 & $\begin{array}{l}31.38 \\
(6.6 \%)\end{array}$ & $\begin{array}{l}30.7 \\
(8.4 \%)\end{array}$ & $\begin{array}{l}29.87 \\
(0.8 \%)\end{array}$ & $\begin{array}{l}29.09 \\
(1.2 \%)\end{array}$ \\
\hline & 15 & $\begin{array}{l}35.49 \\
(4.4 \%)\end{array}$ & $\begin{array}{l}36.53 \\
(6.8 \%)\end{array}$ & $\begin{array}{l}34.28 \\
(2.8 \%)\end{array}$ & $\begin{array}{l}33.67 \\
(1.5 \%)\end{array}$ \\
\hline & 10 & $\begin{array}{l}40.32 \\
(3.9 \%)\end{array}$ & $\begin{array}{l}40.05 \\
(5.8 \%)\end{array}$ & $\begin{array}{l}40.06 \\
(1.4 \%)\end{array}$ & $\begin{array}{l}39.18 \\
(1.6 \%)\end{array}$ \\
\hline \multirow[t]{3}{*}{$\begin{array}{l}\text { Perm. Coef. K } \\
(\mathrm{mm} / \mathrm{s})\end{array}$} & 20 & $\begin{array}{l}19.81 \\
(6.5 \%)\end{array}$ & $\begin{array}{l}19.54 \\
(11.3 \%)\end{array}$ & $\begin{array}{l}15.3 \\
(0.6 \%)\end{array}$ & $\begin{array}{l}13.79 \\
(4.1 \%)\end{array}$ \\
\hline & 15 & $\begin{array}{l}24.24 \\
(10.8 \%)\end{array}$ & $\begin{array}{l}26.66 \\
(3.9 \%)\end{array}$ & $\begin{array}{l}21.05 \\
(5.8 \%)\end{array}$ & $\begin{array}{l}20.26 \\
(7.1 \%)\end{array}$ \\
\hline & 10 & $\begin{array}{l}31.87 \\
(4.6 \%)\end{array}$ & $\begin{array}{l}29.77 \\
(6.5 \%)\end{array}$ & $\begin{array}{l}27.92 \\
(13.9 \%)\end{array}$ & $\begin{array}{l}27.9 \\
(2.1 \%)\end{array}$ \\
\hline
\end{tabular}

values of DoC, the influence of the increment of paste content is proportionally smaller.

The increase of the DoC produces a statistically significant decrease in the porosity and the permeability estimated for the same A/P ratio with the numerical models ( $p$-value $<0.01$ in all ANOVA comparisons and $p$-value $<0.05$ for $75.0 \%$ of multiple comparisons in the Tukey's HSD test). This confirms the observations from the experimental program.

\subsection{Comparison with experimental results}

Fig. 9 shows the numerical results of porosity and permeability for all models. The permeability of the models ranges between 8 and $33 \mathrm{~mm} / \mathrm{s}$, increasing with the porosity. As observed in the experimental results, the permeability coefficient is more influenced by the DoC than by the P/A ratio for the range of variables considered in this study.

Notice that models with the same DoC reach different levels of porosity in the DEM simulation of the compaction process. Likewise, models with approximately the same porosity, show differences in terms of permeability coefficient derived from the CFD. This demonstrates that the DEM-CFD model takes into account the randomness involved in the distribution of the aggregates inside the specimen. Therefore, not only it provides the absolute properties (porosity and permeability coefficient), but also an approximation of the scatter expected due to such randomness.

A comparison between the numerical and experimental results of permeability depending on the porosity is also given in Fig. 9. The experimental results show higher scatter than the numerical results.

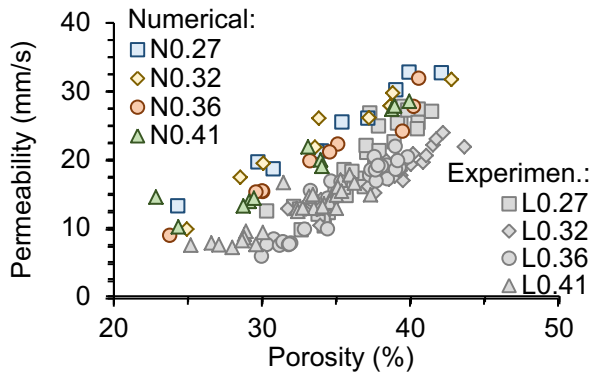

Fig. 9. Numerical and experimental variation of permeability coefficient in relation to the porosity. 

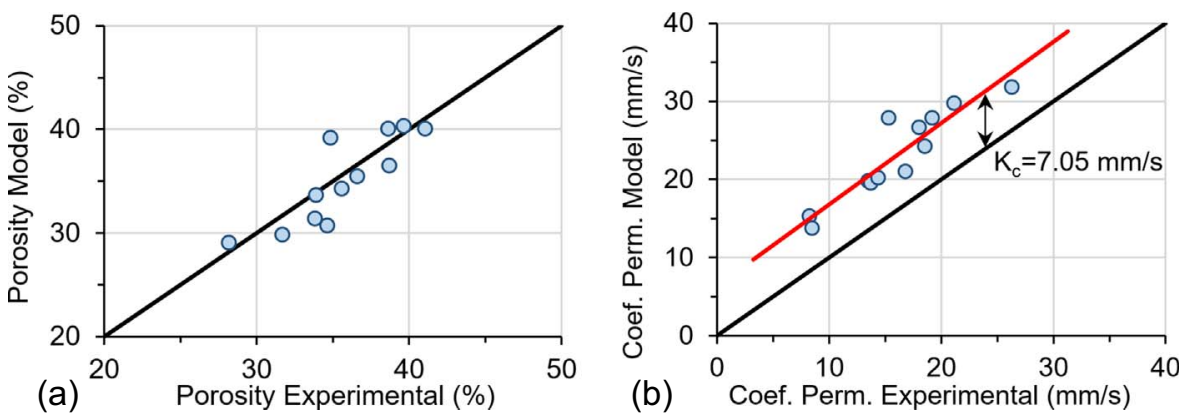

Fig. 10. Direct comparison between average numerical and experimental results for the same P/A ratio and DoC: porosity (a) and coefficient of permeability (b).
This is reasonable since the model only accounts for the randomness induced by the position of the particles distribution. Consequently, they do not include any variability induced by the testing method, which contributes to increase the scatter of the experimental results.

In terms of absolute values, bigger permeability coefficients are calculated for the numerical model. It is important to remark, nevertheless, that no fit of parameters was performed in the simulations. In fact, the results obtained are the consequence of introducing in the models the most likely values of the input parameters found in the literature, most of which are known physical properties. Furthermore, the high complexity of the phenomenon simulated (combining the procedure of compaction and fluid flow) should also be taken into account. In light of that, the differences between the numerical model and the experimental results may be considered small. This highlights the capability of the numerical approach to simulate the behavior of PC expected in reality, being sensible to variations in the composition and in the production process.

Fig. 10a shows a comparison between the average experimental and numerical porosity calculated for the same DoC and P/A ratio. In the same figure, the equivalence line $(\mathrm{x}=\mathrm{y})$ is also presented. The analyses are conducted taking into account the concepts of trueness and of precision of a prediction, following the conceptual definition proposed by the ISO 5725-1 [39]. The trueness indicates how close experimental and numerical values are from each other, being calculated as the average difference between the numerical and the experimental results. The precision indicates how values tend to vary around the average, being calculated as the standard deviation of the differences between the numerical and the experimental results. In both cases, small values show high trueness and precision, that is, an accurate estimation with the numerical model.

Results reveal that the numerical porosity approaches the experimental one. The average trueness of the prediction of the porosity with the numerical model is $0.55 \%$ and the precision is $2.17 \%$. Such values confirm the high capacity of the model to assess the porosity generated by the compaction process.

Fig. 10b shows the direct comparison of experimental and numerical permeability coefficients for mixes with the same DoC and P/A ratio. Once more, the numerical model gives values that are above those measured experimentally for the same condition. A linear trend of the numerical results is presented in the graph. Observe that this linear trend is nearly parallel to the equivalence line $(\mathrm{x}=\mathrm{y})$. This suggests an approximately constant difference between numerical and experimental results, regardless of the P/A ratio and the DoC applied. The trueness of the estimations of the permeability is $-7.05 \mathrm{~mm} / \mathrm{s}$, which represents an average error of prediction equal to $48 \%$.

Such a considerable difference may be attributed to 2 factors. The simplification made regarding the shape of aggregates - considered here as perfect spheres - should create pore structures with smaller tortuosity than the observed in reality for irregular shaped aggregates, thus increasing the permeability in numerical models. Moreover, the size distribution of the aggregates assumed in the model with 3 different diameters of particles also contribute to this outcome. In reality, a bigger variety of dimension of particles should exist, increasing the tortuosity of the porous system and reducing the permeability.

In order to compensate for the influence of these simplifications, a linear regression was performed using the experimental permeability and the permeability obtained with the simulation as independent variable to obtain the corrected numerical permeability $\left(K_{n, a d j}\right)$. The final equation to find $K_{n, \text { adj }}$ is presented in Eq. (8). In this equation, $K_{m}$ is the permeability obtained with the numerical simulation and $K_{C}$ is the correction factor, which is a constant and equal to 7.05 for all mixes considered here. Notice that the same factor is applied to all models, regardless of $\mathrm{P} / \mathrm{A}$ ratio and $\mathrm{DoC}$

$K_{n, a d j}=K_{m}-K_{c}$

Fig. 11a presents the relation between permeability coefficient and porosity for the experimental results and for the numerical results calculated with Eq. (8). Likewise, Fig. 11b shows the comparison between experimental and numerical (obtained in Eq. (8)) permeability coefficients for the same P/A ratio and DoC. The trueness of the adjusted results is $0.00 \mathrm{~mm} / \mathrm{s}$ and the precision is $2.27 \mathrm{~mm} / \mathrm{s}$, with an average error of prediction of $0.11 \%$.

Even though the same correction was applied for the wide variety of mixes and degrees of compaction included in this study, a good agreement between experimental and numerical results was obtained. This indicates that small corrections to account for the simplifications in the definition of the geometries are enough to achieve a robust model, sensible to variations in the $\mathrm{DoC}$ and in the $\mathrm{P} / \mathrm{A}$ ratio.

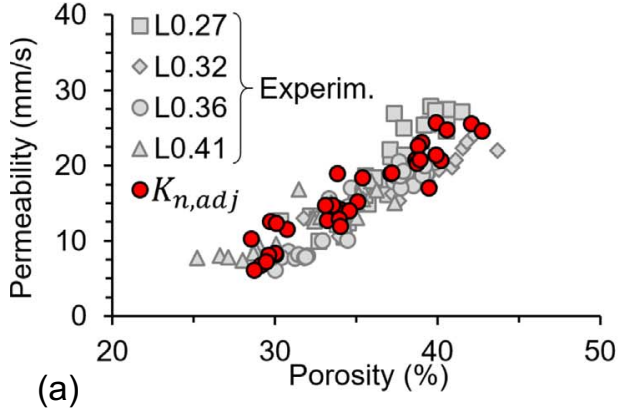

(a)

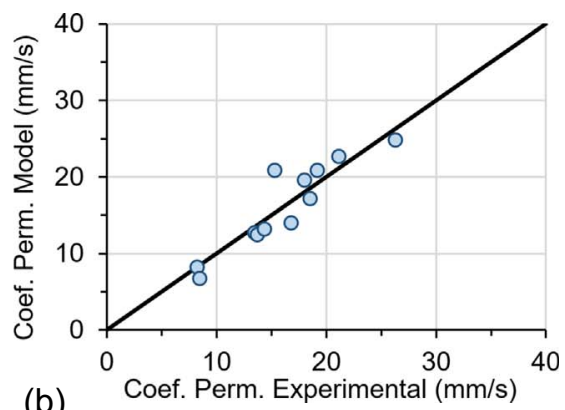

Fig. 11. Adjusted numerical and experimental permeability coefficient: in relation to the numerical porosity (a) and direct comparison (b). 


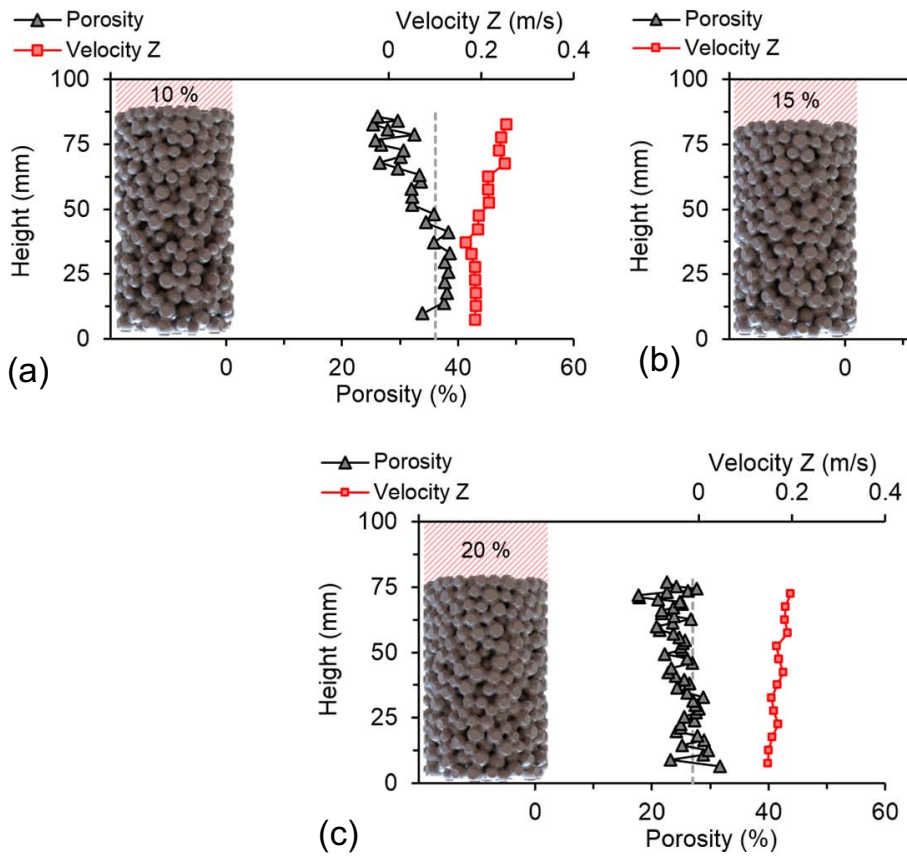

\subsection{Geometric properties}

The effective compaction energy applied varies along the axis of the specimen. Consequently, differences in the porosity should also be expected along the axis Z. The study of the porosity profile compared to the profile of the average velocity in the direction of the flow (Z) is important to understand how the compaction process affects the permeability. In order to establish porosity profile for the different degrees of compaction, models were dived in slices perpendicular to the $\mathrm{Z}$ direction. For each slice, the sectional porosity was determined. Fig. 12 presents the porosity profile of the numerical models with P/A ratio of 0.273 and different DoC, as well as the profile of the average flow velocity estimated numerically.

The smallest values of porosity are observed in slices closer to the surface of the model that received the compaction loads, indicating a more intensive reorganization of the particles at this part of the sample. The particle-to-particle stress dissipates the forces that are not fully transmitted to the adjacent slices. This trend becomes less evident as the average degree of compaction increases. In fact, for high degrees of compaction, the structure of the top layers practically does not change, which forces a rearrangement of the bottom layers. Therefore, a smaller variation of the porosity is observed along the axis of the specimen.

The velocity profile follows the opposite trend, being higher for the top sections and smaller for the bottom ones. Such outcome may be explained by the continuity principle. In steady state, the same volume of water passes through each layer per time interval. Given that the top layers are less porous, they present less space to accommodate the flow of water. Consequently, high velocities have to be achieved to keep constant the total volume of water flowing. On the contrary, in the layers with higher porosity, more space is left, hence smaller velocities are needed to keep the flow constant.

Even though the porosity profile by layer was not quantified experimentally in this study, the numerical results derived from the simulations are in line with the experimental program by [40,41]. As observed here in the simulations [40,41], showed that a difference in the level of compaction of adjacent slices might occur depending on the compaction degree and the proximity with the application of the compaction load.

Such observation provides valuable information that help understand the potential importance of explicitly simulating the compaction process prior to assessing the permeability. An alternative approach would be to generate a meso-structure with an algorithm that define the position of particles to guarantee a porosity representative of a certain DoC. Even though this approach is feasible, the reproduction of the nonhomogeneities of the sample and the variation of the porosity profile caused by the compaction would imply several assumptions. In this context, it stands to reason that a random generation of the mesostructure of the hardened PC may not provide a prediction as accurate as when the compaction process is also simulated. This supports the use of the DEM-CFD model for the prediction of the permeability coefficient.

\subsection{Tortuosity}

Certain aspects of the fluid flow inside the specimen are difficult to assess experimentally. This is the case of the fluid flow streamline and its relation with the tortuosity, which are easier to analyze by means of numerical models. Fig. 13 presents horizontal and vertical cross-sections of the model with P/A ratio of 0.27 and DoC of $15 \%$ in which the velocity in $\mathrm{Z}$ direction is plotted. In order to understand better how the fluid flow is influenced by the solid phase, a region of Fig. 13b is scaled. In this region, arrows indicate the flow direction. An abrupt change in the direction of the flow occurred when the fluid impacted against the solid phase. This results in a dissipation of the velocity of the fluid flow.

Fig. 14a shows the fluid flow streamline at the steady-state. The variation of the velocity with the size of the connected pores is better observed in Fig. 14b. As mentioned previously, the velocity is strongly dependent on the size and the connectivity of the pores. Their influence may be lumped together in a single parameter called tortuosity factor.

The tortuosity is determined here by dividing the height of the model by the length of the average path taken by the fluid that passes through the specimen. A large number of possible paths exist inside a specimen. In order to establish a number of paths needed to achieve a representative tortuosity of a model, a sensitivity analysis was conducted. It was found that 900 paths randomly selected were needed to obtain stable values for the tortuosity.

The relation between the porosity and the tortuosity for the models is depicted in Fig. 14c for mixes with different P/A ratios. The influence of the P/A ratio in the tortuosity is negligible for the range of input parameters, mix compositions and DoC considered here. This is 


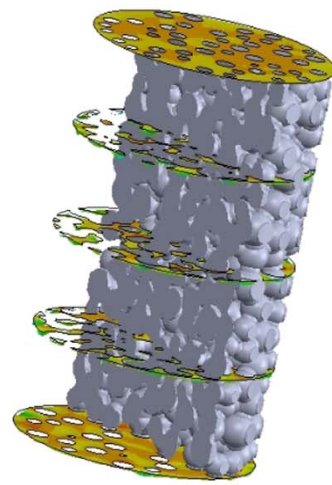

(a)



(b)

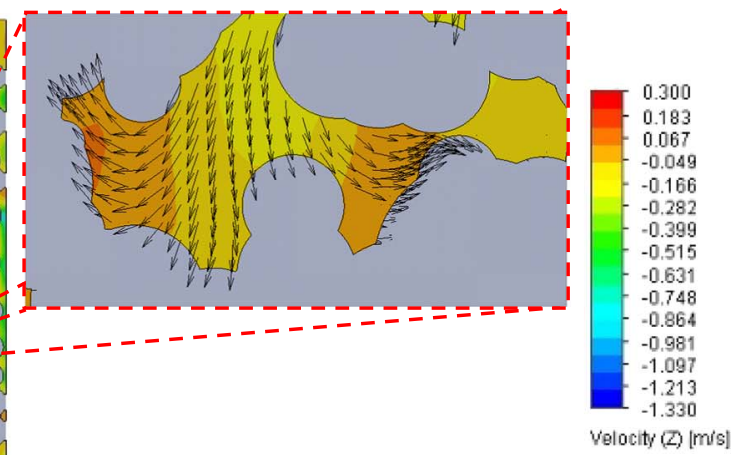

Fig. 13. Plot of the velocity in the fluid flow main direction (direction $\mathrm{Z}$ ).

reasonable since the increment in the mortar layer involving the aggregates due to increase in the paste content is small in relation to the total porosity of the PC, not modifying the path of the flow streamline significantly.

On the other hand, the tortuosity increases considerably with the decrease of the porosity. A non-linear relation seems to exist between both parameters. Since the permeability coefficient is affected by the combined influence of the porosity and the tortuosity, a non-linear relation should also exist between the porosity and the permeability coefficient. This observation derived from the numerical results is in line with the hypothesis proposed in Section 2.3, justifying the increase of the permeability observed in Fig. 3 and Fig. 9a.

In this sense, a nonlinear regression was performed using the porosity as independent variable to obtain the tortuosity. The final equation to find the numerical tortuosity $\left(\tau_{\text {num }}\right)$ is presented in Eq. (9). A good fit is obtained between the estimation with Eq. (9) and the simulations. The comparison of results for equivalent porosity shows a correlation coefficient $\left(\mathrm{R}^{2}\right)$ of 0.887 .

$\tau_{\text {num }}=0.9+\frac{10}{P}$

\section{Conclusions}

This study shows the combined use of numerical models to predict the compaction process and the permeability of pervious concrete. Results obtained with these models are compared with the obtained in an experimental program. The following conclusions may be derived based on this analysis.

- The differences between the numerical and experimental permeability are mainly caused by simplifications in the shape and size of the aggregate assumed in the models to reduce the calculation cost. To compensate for this approximation, a linear correction of the numerical results should be performed according with Eq. (8). Notice that this correction is the same for the whole experimental program conducted, regardless of the $\mathrm{P} / \mathrm{A}$ ratio and the compaction degree.

- After the correction, the trueness of the prediction of the permeability with the numerical model was $0.00 \mathrm{~mm} / \mathrm{s}$, with a precision of $2.27 \mathrm{~mm} / \mathrm{s}$. The average error of prediction was of $0.11 \%$. These values may be considered small given the complexity of the simulations and the fact that no fit of input parameters was performed to adjust the results from the model.

- Both the numerical and the experimental results confirm that the permeability is more affected by variations in the DoC than by variations in the $\mathrm{P} / \mathrm{A}$ ratio for the ranges considered here.

- Models with the same P/A ratio and DoC present slightly different permeability. This is a consequence of the approach used to generate the meso-structure, which accounts for the intrinsic variability induced by the position of particles. Consequently, the DEM-CFD model not only provides an estimation of the absolute permeability but also of the scatter of this property.

- The DEM-CFD model offers insight about the velocity distribution related to the porosity profile along the axis of the PC specimen, making possible the assessments of parameters that hardly ever could be obtained experimentally, such as the tortuosity. No clear relation between the tortuosity and the P/A ratio was found, probably due to the similarity of the channels created by the interconnected pores. Conversely, the tortuosity decreases exponentially with the porosity. Since the permeability depends on both the porosity and the tortuosity, this explains why in the numerical and the



(a)

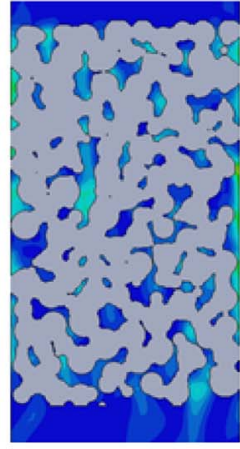

(b)



Fig. 14. Flow streamline (a), velocity in the cross section (b) and tortuosity in relation to the porosity (c).



(c) 
experimental studies the permeability increases almost exponentially with the porosity.

- The DEM-CFD model proposed here is capable of predicting the experimental permeability of PC compositions with different P/A ratios and compaction degrees. This opens up the possibility of performing a numerical design of compositions and production processes before conducting experiments, which might reduce the number of tests needed to achieve the composition that best suits the permeability required in each application.

\section{Acknowledgements}

The corresponding author thanks the EDUCATIONAL MINISTRY OF SPAIN for the FPU Scholarship (AP2012-4188). The authors thank the companies $\mathrm{CPV}$ and BASF for the dedication to several research projects (especially HoPo) throughout the years, and acknowledge the economic support provided by the Spanish Ministry of Science and Innovation through the project BIA2013-49106-C2-1-R.

\section{References}

[1] D. Castro-Fresno, J. Rodríguez-Bayón, J. Rodríguez-Hernández, F. Ballester-Muñoz, Sustainable urban drainage systems (SUDS), Interciencia 30 (5) (2005) (pp. $255-260+306-308)$.

[2] D. Castro-Fresno, V.C. Andres-Valeri, L.A. Sañudo-Fontaneda, J. RodríguezHernández, Sustainable drainage practice in Spain, specially focused on pervious pavements, Water (Switzerland) 5 (1) (2013) 67-93.

[3] F. Giustozzi, Polymer-modified pervious concrete for durable and sustainable trasnportation infraestructures, Constr. Build. Mater. 111 (May 2016) 502-512.

[4] A. Ibrahim, E. Mahmoud, Y. Mohammed, V.C. Patibandla, Experimental study on Portland cement pervious concrete mechanical and hydrological properties, Constr. Build. Mater. 50 (2014) 524-529.

[5] M. Scholz, S.M. Charlesworth, S.J. Coupe, Drainage benefits of porous, permeable and pervious paving, Water Resources in Built Environment: Management Issues and Solutions, May 2014, pp. 302-318.

[6] E. Gómez-Ullate, E. Castillo-López, D. Castro-Fresno, J.R. Bayon, Analysis and contrast of different pervious pavements for management of storm-water in a parking area in Northern Spain, Water Resour. Manag. 25 (6) (2011) 1525-1535.

[7] L. Ferrara, A. Caverzan, A. Peled, Collapsible lightweight aggregate concrete - part I: material concept and preliminary characterization under static loadings, Mater. Struct. 49 (5) (May 2016) 1733-1745.

[8] L. Ferrara, A. Caverzan, L. Nahum, A. Peled, Collapsible lightweight aggregate concrete - part II: characterization under static and dynamic loadings, Mater. Struct. 49 (5) (May 2016) 1747-1760.

[9] E.F. O'Neil, W. Shen, H.M. Jennings, J.J. Thomas, T. Cummins, Development of frangible concrete to reduce blast-related casualties, ACI Mater. J. 109 (1) (2012) $31-40$.

[10] W. Nian, K.V.L. Subramaniam, Y. Andreopoulos, Experimental investigation of blast-pressure attenuation by cellular concrete, ACI Mater. J. 112 (2015) 21-28.

[11] N. Gafoori, S. Dutta, Laboratory investigation of compacted no-fines concrete for paving materials, J. Mater. Civ. Eng. 7 (3) (1995) 183-191.

[12] C. Gaedicke, A. Marines, F. Miankodila, Assessing the abrasion resistance of cores in virgin and recycled aggregate pervious concrete, Constr. Build. Mater. 68 (2014) 701-708.

[13] M. Sonebi, M.T. Bassuoni, Investigating the effect of mixture design parameters on pervious concrete by statistical modelling, Constr. Build. Mater. 38 (2013) 151-160.

[14] R. Pieralisi, S.H.P. Cavalaro, A. Aguado, Evolutionary lattice model for the compaction of pervious concrete in the fresh state, Constr. Build. Mater. 99 (2015) 11-25, http://dx.doi.org/10.1016/j.conbuildmat.2015.08.

[15] R. Pieralisi, S.H.P. Cavalaro, A. Aguado, Discrete element modelling of the fresh state behavior of pervious concrete, Cem. Concr. Res. 90 (2016) 6-8, http://dx.doi. org/10.1016/j.cemconres.2016.09.010.

[16] M.T. Suleiman, J.T. Kevern, V.R. Schaefer, K. Wang, Effect of Compaction Energy on Pervious Concrete Properties, Proceedings of the 2006 NRMCA Concrete Technology Forum - Focus on Pervious Concrete, Nashville, TN, (2006).

[17] M.S. Sumanasooriya, D.P. Bentz, N. Neithalath, Planar image-based reconstruction of pervious concrete pore structure and permeability prediction, ACI Mater. J. 107 (4) (2010) 413-421.

[18] S.-Y. Chung, T.-S. Han, S.-Y. Kim, T.-H. Lee, Investigation of the permeability of porous concrete reconstructed using probabilistic description methods, Constr. Build. Mater. 66 (15) (2014) 760-770.

[19] L. Akand, M. Yang, Z. Gao, Characterization of pervious concrete through image based micromechanical modeling, Constr. Build. Mater. 114 (2016) 547-555.

[20] EN 12390-1, Testing Hardened Concrete - Part 1: Shape, Dimensions and Other Requirements for Specimens and Moulds, AENOR (16 p), (2013).

[21] ASTM, C1754/C1754M-12, Standard Test Method for Density and Void Content of Hardened Pervious Concrete, ASTM International, West Conshohocken, PA, 2012.

[22] A. Yahia, K.D. Kabagire, New approach to proportion pervious concrete, Constr. Build. Mater. 62 (2014) 38-46.

[23] W. Yeih, T.C. Fu, J.J. Chang, R. Huang, Properties of pervious concrete made with air-cooling electric arc furnace slag as aggregates, Constr. Build. Mater. 93 (2015) $7337-7745$.

[24] M.A.R. Bhutta, N. Hasanah, N. Farhayu, M.W. Hussin, M.B.M. Tahir, J. Mirza, Properties of porous concrete from waste crushed concrete (recycled aggregate), Constr. Build. Mater. 47 (2013) 1243-1248.

[25] W.-T. Kuo, C.-C. Liu, D.-S. Su, Use of washed municipal solid waste incinerator bottom ash in pervious concrete, Cem. Concr. Compos. 37 (2013) 328-335.

[26] V. Sata, A. Wongsa, P. Chindaprasirt, Properties of pervious geopolymer concrete using recycled aggregates, Constr. Build. Mater. 42 (2013) 33-39.

[27] Y. Zaetang, A. Wongsa, V. Sata, P. Chindaprasirt, Use of lightweight aggregates in pervious concrete, Constr. Build. Mater. 48 (2013) 585-591.

[28] T. Tho-in, V. Sata, P. Chindaprasirt, C. Jaturapitakkul, Pervious high-calcium fly ash geopolymer concrete, Constr. Build. Mater. 30 (2012) 366-371.

[29] P.A. Cundall, A Computer Model for Simulating Progressive Large-scale Movement in Block Rock Mechanics, Proc. Symp. Int. Soc. Rock Mech. Nancy, (1971), p. 2.

[30] P.A. Cundall, O.D.L. Strack, BALL - A Program to Model Granular Medium Using the Distinct Element Method, Technical Note: Advanced Technology Group, London, (1978).

[31] Šmilauer, V., Catalano, E., Chareyre, B., Dorofeenko, S., Duriez, J., Gladky, A. Kozicki, J., Modenese, C., Scholtès, L., Sibille, L., Stránský, J., Thoeni, K., Yade Documentation 2nd ed. The Yade Project. http://yade-dem.org/doc/.

[32] S. Remond, P. Pizette, A DEM hard-core soft-shell model for the simulation of concrete flow, Cem. Concr. Res. 58 (2014) 169-178.

[33] J. Zheng, X. An, M. Huang, GPU-based parallel algorithm for particle contact detection and its application in self-compacting concrete flow simulations, Comput. Struct. 112-113 (2012) 193-204.

[34] N.S. Klein, J. Bachmann, A. Aguado, B. Toralles-Carbonari, Evaluation of the wettability of mortar component granular materials through contact angle measurements, Cem. Concr. Res. 4 (12) (2012) 1611-1620, http://dx.doi.org/10.1016/ j.cemconres. 2012.09.001.

[35] Dassault Systèmes, Advanced Boundary Cartesian Meshing Technology in Solidworks Flow Simulation, Dessault Systèmes, 2013, p. 31 (Technical paper).

[36] A. Sabachkin, G. Dumnov, Numerical Basis of CAD-embbed CFD. National Agency for Finite Element Methods and Standards (NAFEMS), World Congress, Salzburg, Austria, 2013, p. 20.

[37] K.L. Apedo, C. Munzer, H. He, P. Montgomery, N. Serres, C. Fond, F. Feugeas, Cement paste surface roughness analysis using coherence scanning interferometry and confocal microscopy, Mater. Charact. 100 (2015) 108-119.

[38] Dassault Systèmes, Technical Reference SolidWorks Flow Simulation, (2014), p. 68.

[39] ISO 5725-1, Accuracy (Trueness and Precision) of Measurement Methods and Results. General Principles and Definitions, British Standards Document, (1994) (26p).

[40] W.D. Martin, B.J. Putman, N.B. Kaye, Using image analysis to measure the porosity distribution of a porous pavement, Constr. Build. Mater. 48 (2013) 210-217.

[41] W.D. Martin, N.B. Kaye, B.J. Putman, Impact of vertical porosity distribution on the permeability of pervious concrete, Constr. Build. Mater. 59 (2014) 78-84. 